\title{
An Observational Study on Barbers' Practices and Associated Health Hazard in Fiji
}

\author{
Dip Chand ${ }^{1}$, Masoud Mohammadnezhad ${ }^{1} \&$ Sabiha Khan ${ }^{1}$ \\ ${ }^{1}$ School of Public Health and Primary Care, Fiji National University, Suva, Fiji \\ Correspondence: Associate Professor Dr Masoud Mohammadnezhad, School of Public Health and Primary Care, \\ Fiji National University. Tel: +679-97-26-127. E-mail: masraqo@hotmail.com
}

Received: January 20, 2022 Accepted: February 28, 2022 Online Published: March 1, 2022

doi:10.5539/gjhs.v14n3p108 URL: https://doi.org/10.5539/gjhs.v14n3p108

\begin{abstract}
Background: The barbers' work is associated to many infectious diseases which lead to major cause of morbidity and mortality in human's population globally. This study aimed to determine barbers' practices and health hazards associated with their profession in Fiji.

Materials and Methods: A cross sectional quantitative study was conducted to collect data from 50 observational sessions among barbers in Suva, Fiji in 2020. A sample of 25 barbers were randomly selected to participate in this study. A checklist was used to record and collect data. Out of the 25 barbershops observed none of them carried out any form of sterilization.

Results: Only 4 (16\%) did some form of disinfection with home bleach and savalon randomly while $84 \%$ did not have any form of decontamination in place. The results further illustrate that $22(88 \%)$ of the disinfection were not potent while $3(12 \%)$ were unknown. Similarly, $22(88 \%)$ had inappropriate methods of disinfection and $3(12 \%)$ were questionable. None of the barbershops observed had supply of hot water and only $15(60 \%)$ had sufficient privy and hand washing facilities. Furthermore, only $6(24 \%)$ used PPEs compared to $19(76 \%)$ were in non-compliance.
\end{abstract}

Conclusion: This finding calls for immediate attention of authorities to enforce relevant laws and create awareness and training to improve standards in barbering profession.

Keywords: barbering instruments, health hazards, decontamination, Fiji, observation, practices

\section{Introduction}

The current estimated burden of infectious diseases in Fiji is around 18.4\% which are preventable and treatable as well (MOHMS Fiji, 2017), but continue to thrive owing to ignorance to personal and environmental hygiene including poor political commitment to public health over clinical services (Chaudhry et al., 2010). According to the World Bank (WB) and World Health Organization (WHO) report "Tracking progress towards Universal Health Coverage", millions of people globally have insufficient provision of essential health services (WHO \& WB, 2015). Furthermore "The global epidemiology of infectious diseases" report states that many families in Low- and Middle Income Countries (LMICs) are propelled into utmost poverty due to excessive health care costs (WHO, 2006). Currently, at least half of the world's population do not have access to health services they need (Lopez et al., 2006). The lack of equipment's and medicine, water and electricity; shortages of doctors; prohibitive costs; obsolete infrastructure of hospitals and clinics; poorly trained nurses and midwives; they all stand in the way of providing good quality healthcare to all. This must change (Kruk et al., 2018).

The above situations aggravate the delivery of health care services in developing countries, where infectious diseases are the major cause of all human deaths, killing more than 11 million people annually apart from diminishing the lives of countless others (Downey, 2005; Abia et al., 2016). Furthermore, infectious diseases related to barbers' profession remains the major cause of morbidity and mortality in human beings particularly in developing and underdeveloped countries (Wazir et al., 2008). Even though many infectious diseases are preventable and treatable in developing countries, personal, environmental and food hygiene, poor water and sanitation (WASH) pollution caused by poor waste management, ignorance to Good Hygiene Practices (GHP) and poor political commitments persist (Khandiat et al., 1999).

There are several transmission modes of infectious diseases however the most common routes of transmission in 
barbershops include airborne, faeco-oral, infected instruments and direct spread through person-to-person transmission (Amodio et al., 2010; James et al., 2017). Since barbers' profession involves cutting any type of hair, give shaves, and trim beard which are potential routes of transmission to several infectious diseases which increases the burden of infectious diseases in many developing and under developed countries (Almasi et al., 2016). In view of the above barbering operations in Fiji may expose a large proportion of its clients with several health hazards silently if preventive measures are continued to be ignored as demonstrated by previous studies. (Amir \& Raymond, 2005; Shahid et al., 2013). Considering the grave consequences of infections especially Hepatitis, HIV and recent outbreak of COVID19, related to barbers' profession; bona fide barbering practices is imperative to control infections associated with this profession (Janjua \& Nizamy, 2002).

The frequency and severity of Communicable Disease (CD) out breaks in Fiji is well documented. Despite this, there had been no previous study carried out in Fiji neither in Pacific Island Countries (PIC) in particular on barbers to gauge their practices that may be helpful to eliminate and prevent many common CDs associated with barbering profession. In addition, lack of relevant literature on many data base on the research topic and many studies cited did not avail full text therefore only abstracts were used.

Since Fiji is a small island nation, and barbering profession is considered as small and medium enterprises (SME) that provides employment opportunities to school drop outs and substantially contributes to Fiji's economic growth. In this regard barbershop standard is well stipulated in the Public Health Act and Regulations which forms the basic standards on the Hair Dresser and Chiropractor practices in the country. These standards were formulated by the Colonial British Government which is still very much practical. Despite having stringent laws in place, the enforcement of these Laws are still neglected by the relevant authorities especially in barbershops when inspections are carried out for annual licensing. However, Hair salons and beauty salons which are niche market for higher class including tourism have higher rate of compliance and standards which would be a bench mark for compliance in barbershops that serves ordinary Fijians at an affordable cost. Therefore, the purpose of the study was to observe practices and health hazards associated with barber's profession in Suva Fiji and to bench mark against regulated standards of practice as per Public Health Act and Regulations. The results of this study will help the health authorities to understand the dynamics of disease transmission and design appropriate interventions in relation to barbering profession in Fiji which serves majority of the ordinary Fijians.

\section{Materials and Methods}

\subsection{Study Design and Settings}

A cross-sectional study was conducted to observe practices and health hazards associated with barber's profession between June and November 2020 in Suva, Fiji which also serves as the national and regional hub for Fiji and the Pacific respectively. There were 48 barbershops operating at the time of this study.

\subsection{Study Sample}

All the barbershops operating in Suva were considered as study population. Out of 48 barbershops that were in operation during the time of study, a sample size of 25 barbers were randomly selected for this study. The inclusion criteria applied was all those barbershops that were operating at least for 6 months in Suva and were currently licensed. Beauty salons and hair salons were excluded from the study including those barbershops who were hesitant to participate were also excluded. A sample size of 25 barbers were randomly selected for this study.

\subsection{Data Collection Tool}

A checklist was used for the observation. Checklist was developed using relevant literatures (John J, 2011) to fulfill the aim and objective of the study. The observational checklist had 10 sections or areas for observation such as whether any decontamination was practiced, method of decontamination, name of disinfectants, Virucidal potency of the decontamination, appropriateness of the decontamination exercise, accidental cuts, GHP, conditions of the barbershops, adequate supply of hot and cold water, adequate provision of privy facilities and provision of Personal Protective Equipment's (PPEs) to bench mark against Fijis Public Health Act and Regulations on Hairdressers (Kruk et al., 2018). The observation was carried out by the principle researcher at least 2 random sessions to avoid biasness and to maintain the reliability and credibility of the observational sessions conducted.

\subsection{Study Procedure}

Suva City Council (SCC) provided the facility approval and records of barbershops, their locations and other relevant details. The owners of the barbershops were contacted by phone and physical visit by the principle researcher and were explained the purpose of this observational study. The barbershop owners were assured that no disturbances will be caused to the normal operations during the time of observations. Barbershops anonymity and 
privacy of information was assured. A written consent was obtained once the participating barbershop agreed to participate. All barbershop owners were informed of their privilege and right to withdraw from this study at any time. The checklist prepared was used to collect the information while observing the practices. Questions that needed to be responded were asked during the observation session and forms filled accordingly.

\subsection{Data Management and Analysis}

Data was managed manually as per the checklist criteria. The notes taken during the observations was rechecked to ensure that quality is maintained. Data analysis was done using the checklist which was tabulated under different headers. Raw data was entered under each header and frequency and percentage was calculated manually.

\subsection{Ethics Approval}

Ethical approval for the study was obtained from Fiji National University (FNU) College of Health Research Committee (CHREC) and the facility approval was also obtained from SCC. For data collection all barbershop owners were informed through the information sheet the purpose of the visit and documented consents were secured from barbershop owners.

\section{Results}

\subsection{Demographic Characters of Participants}

Twenty-five barbers representing the entire traceable barbers in the study area were interviewed during the observational sessions. The age of the participants ranged between 18 and 39 years. When grouped, age group 18-29 years predominated at 18 (72\%). Hundred percent of the barbers were males and Fijians of Indian descent. Major religion practiced were Hinduism among majority respondents. Sixteen (64\%) were currently married and $100 \%$ had secondary level of education. All the participants earned \$150 to \$250 Fijian Dollars per week. All barbershops were in operation for more than 4 years and non-had undergone any form of training (Table 1).

Table 1. Demographic characteristics of participants $(n=25)$

\begin{tabular}{lll}
\hline Characteristics & Frequency & Percentage \\
\hline Age & 18 & 72 \\
$18-29$ years & 7 & 28 \\
$30-39$ years & 25 & 100 \\
\hline Sex (Gender) & & 100 \\
Male & 25 & \\
Race & 21 & 84 \\
\hline Fijian of Indian Decent & 4 & 16 \\
Religion & 4 & 64 \\
Hindu & 16 & 36 \\
Muslim & 9 & 100 \\
\hline Marital Status & & \\
Currently married & 25 & 100 \\
Never married & & 100 \\
\hline Education Level & 25 & 100 \\
Secondary & & \\
\hline Weekly Income & 25 & \\
$\$ 150-\$ 250$ & 25 & \\
\hline Duration of Practice & & \\
$>4$ years & & \\
\hline Training received & No & \\
\hline
\end{tabular}




\subsection{Barbers Practices}

Out of the 50 barbering sessions observed, $100 \%$ use equipment's such as electrical clippers, scissors, razors, barber blades, combs, hair brush, save brush, cape, neck duster, hand mirror, powder puff and water sprayer.

As Table 2 shows, out of the 25 barbershops observed only 4 (16\%) did some form of disinfection with home bleach and savalon randomly while $84 \%$ did not have any form of decontamination in place. The results also reveal that none of the 25 barbershops observed carry out any form of sterilization of barbering equipment's while only $16 \%$ used some form of chemical decontamination and $84 \%$ had no means of decontaminating there barbering equipment's. In terms of using disinfectant, the results showed that only $4 \%$ used Methylated spirits with $10 \%$ methanol, Sodium hypochlorite (Janola-home bleach) and Savalon while majority (88\%) did not use any form of chemicals or sterilization.

Table 2. Participants practices $(\mathrm{n}=25)$

\begin{tabular}{lll}
\hline Factors & Frequency & Percentage \\
\hline Instrument decontamination done? & & \\
Yes & 4 & 16 \\
No & 21 & 84 \\
\hline Method of Instrument Decontamination & & \\
Sterilization & 0 & 0 \\
Disinfection & 4 & 16 \\
None & 21 & 84 \\
\hline Name of disinfectant used & & \\
Methylated spirits with 10\% methanol & 1 & 4 \\
Sodium hypochlorite (Janola- Bleach) & 1 & 4 \\
Savalon & 1 & 4 \\
Others & 22 & 88 \\
\hline
\end{tabular}

Table 3 illustrates that twenty-two $(88 \%)$ of the disinfection were not potent while $3(12 \%)$ were unknown. Similarly, $22(88 \%)$ had inappropriate methods of disinfection and $3(12 \%)$ were questionable. During the observations, 2 (8\%) sessions involved incidental cuts and only $14(56 \%)$ had GHP and their barbershops in good order. None of the barbershops observed had supply of hot water and only $15(60 \%)$ had sufficient privy and hand washing facilities. Furthermore, only 6 (24\%) used PPEs compared to $19(76 \%)$ were in non-compliance.

Table 3. Observation results $(\mathrm{n}=25)$

\begin{tabular}{lll}
\hline Factors & Frequency & Percentage \\
\hline Virucidal potency of the decontamination & & \\
Potent & 0 & 0 \\
Not potent & 22 & 88 \\
Unknown & 3 & 12 \\
\hline Appropriateness of the decontamination exercise & 0 & 0 \\
Appropriate & 22 & 88 \\
Inappropriate & 3 & 12 \\
Questionable & & \\
\hline Accidental cut & 2 & 8 \\
Yes & 23 & 92 \\
No & & \\
\hline GHP \& Barbershop in Good order & 14 & 56 \\
Yes & 11 & 44 \\
No & & \\
\hline
\end{tabular}




\begin{tabular}{lll}
\hline Adequate supply of Hot and cold water & & \\
Yes & 0 & 0 \\
No & 25 & 100 \\
\hline Sufficient Privy and hand washing facility & 15 & 60 \\
Yes & 10 & 40 \\
No & & \\
\hline PPEs used & 6 & 24 \\
Yes & 19 & 76 \\
No & & \\
\hline
\end{tabular}

\section{Discussion}

This study aimed to determine barbers' practices on health hazard associated with their profession in Fiji. Out of the 25 barbershops observed, all barbers were males and 72\% were between the ages of 18-29 years. All Berbers had education up to secondary school level and non-had any training on barbering. The results also show that out of the 25 barbershops observed none of them carried out any form of sterilization. Only 4 (16\%) did some form of disinfection with home bleach and savalon randomly while $84 \%$ did not have any form of decontamination in place. The results further illustrate that $22(88 \%)$ of the disinfection were not potent while $3(12 \%)$ were unknown. Similarly, $22(88 \%)$ had inappropriate methods of disinfection and $3(12 \%)$ were questionable. During the observations, 2 (8\%) sessions involved incidental cuts and only 14 (56\%) had Good Hygiene Practice (GHP) and their barbershops in good order. None of the barbershops observed had supply of hot water and only $15(60 \%)$ had sufficient privy and hand washing facilities. Furthermore, only 6 (24\%) used PPEs compared to 19 (76\%) which were in non-compliance.

The results of this study revealed that none of them were practicing instrument decontamination and sterilization. Similar views have been reported in previous studies in Iran, (Almasi et al., 2016) South Africa (James et al., 2017) and Pakistan (Shahid et al., 2013). Findings reveal that barbers only clean their instruments with brush, wet cloth and oil the machines when required. The studies did not relate these findings to demographic characteristics however it is believed that most street, road side and corner barber shops do not adhere to best practices as regulated by these countries. Government policies on SMEs to promote income generating avenues in poor communities were the challengers regarding compliance issues by the authorities (James et al., 2017). Studies conducted in South Africa and Rawalpindi Pakistan reported similar findings (Amir \& Raymond, 2005; Janjua \& Nizamy, 2004). Perhaps decontamination is seen as synonyms with routine cleaning of barbering equipment's with wet cloths, and oiling the clippers which is understood as physically clean, regardless of the invisible microbial load on the barbering equipment's. Studies conducted in Pakistan and Ethiopia had similar findings (Janjua \& Nizamy, 2004; Zuwudic et al., 2002). Though provision of hot water for decontamination of instruments is regulated by Public Health Act (PH Act) and Regulations poor awareness and enforcement compelled by political interference, barbershops compliance issues with barbershops have been eroded gradually. Obsolete laws and poor litigation capacity also contributes to non-compliances as stated in other studies (James et al., 2017; Kruk et al., 2018). These findings strongly suggest for aggressive awareness and training by the authorities to meet the minimum requirements.

Observations further revealed that no participant was found to be disinfecting or sterilizing their barbering equipment's before use on each and every client contrary to requirements of the Public Health Act and Regulations of Fiji (PH Act, 1935).

In addition, most of the barbering practices observed posed direct risk of infection from their clients and from clients to clients through contaminated instruments which were neither sterilized nor decontaminated. This agrees with the findings reported among barbers in a study conducted in North-West Ethiopia (Beyen et al., 2012). Barbers are at direct risk of CD infection if they come into contact with an infected person or equipment's especially blood or contagious diseases of the skin including air born viral infections. The risk becomes higher if they have cuts or bruises that are not properly protected, particularly on the arms (Jokhio et al., 2010). Findings revealed that the practice on equipment non decontamination was consistent in all barbershops irrespective of the location and scale of operations. This concludes that barbers lacked knowledge in the areas such as expertise on decontamination/disinfection and sterilization of barbering instruments; lacked recognition on basic infection control and insight on infection transmission and control. A study conducted in Hyderabad Pakistan showed 
similar results (Jokhio et al., 2010). However, this finding is in variance to a study conducted in Oyo State in Nigeria where findings demonstrated high sterilization rate among barbers (Salami et al., 2005). The study, probably needed further investigation whether decontamination procedures were probably administered.

Though majority of participants appeared not to observe the decontamination or sterilization process, only few who did used some form of decontamination which were inappropriately carried out. These findings are similar to studies conducted in Nigeria (Salami et al., 2005) and Bangladesh (Chanda et al., 2004). Standard disinfectants that are recommended for use in health care facilities and personal care settings do recognizes $5.25 \%$ household bleach, 70\% isopropyl alcohol, and iodophors as intermediate level disinfectants which kills the microorganisms for low level disinfectants plus fungi but does not recognize water, wet cloth and oil as disinfectants (Chanda et al., 2004).

On the other hand, observations results revealed that majority of participants do not wear coats/overalls, face mask neither hand gloves while serving clients especially during this COVID19 pandemic. Furthermore, none were using any paper towels, clean and fresh face towels, neck protectors, neck cloths, and other fabrics for each and every customer as required by the Public Health Act of Fiji (Public Health Act, 1935) and the Australia Public Health (Hairdressing) Code of Practice. The finding of this study is similar to studies conducted on barber's practices in Ethiopia (Zuwudic et al., 2002) and the purpose of wearing proper PPEs for barbers and clients may be the consequence of lack of knowledge on infection transmission and prevention.

Results of observational sessions revealed that none of the barbers were practicing the basic hand hygiene practice by washing their hand with soap and clean water after serving each and every client. Hundred percent sessions observed used the same cape for each and every client. Furthermore, there was no screening conducted for clients coming with infectious diseases. Studies conducted in Karachi Pakistan (Almasi et al., 2016) and Kumasi Ghana (Mutocheluh \& Kwarteng, 2015) had similar findings that barbers would attend to any clients who present to them. However, these findings are at variance to studies conducted in developed countries. (Lyons et al., 2013; Amodio et al., 2010; Moda \& King, 2019)

Observations further revealed that majority of the barbers used same brushes with powder on clients to remove hair from shoulder and neck and also for cleaning instruments in the same barbering procedure with the high chances of cross contamination. This finding was also consistent to similar studies conducted in Ethiopia (Beyen et al., 2012) and Cameroon (Kana et al., 1998). Lack of knowledge and awareness on cross contamination and GHP may be the rationale leading to improper practices. Studies suggest that to improve GHP in barbershops Massive, Repetitive, Intensive and Persuasive (MRIP) awareness may be involved (Lopez et al., 2006; Ottawa Charter for Health Promotion, 1986). This finding tends to suggest that authorities need to train, inform and create awareness on all barbershops to standardize the barbering practice. These were similar sentiments expressed in studies conducted in Hyderabad Pakistan and Sokoto Nigeria. (Jokhio et al., 2010; Ibrahim et al., 2007)

In addition, lack of enforcement and monitoring by authorities may be another reason for substandard hygiene practices among barbers. Similar findings have also been revealed in studies conducted in developing countries (Almasi et al., 2016). Contrary to findings in many developed countries where activities of barbers are properly regulated and monitored by way of thorough training and licensing process (Ann, 2006). Fijian authorities have neglected barbers' activities despite having a stringent Public health laws in place. (Public Health Act, 1935)

Incidental cuts are known as skin damage which are preconditions required for infectious diseases to arise. Skin damage during barbering usually happens as an accidental cut or abrasion as a result of blade-to-skin contact or both, increases the potential of infection transmission. In many circumstances incidental cuts and skin damages occur due to blade-to- skin contact or when detachable plastic comb is not used. (TAOD \& HPU, 2002)

All the sessions observed in this study involved procedures which led blade-to-skin contact with increased risk of skin abrasion and cuts. Consequently, two sessions observed actually resulted into accidental cuts on the clients whereby no action was taken to disinfect the instruments concerned and the victims of the cuts. Failure to disinfect instruments and provide first aid to clients due to minor cuts during barbering sessions seem to be regarded as insignificant as reported in several previous studies. (Amodio et al., 2010; Almasi et al., 2016; Ibrahim et al., 2007; Correa \& Gisselquist, 2006) The raise in fashion especially in young Fijians for the zero-cut hairstyle may be a contributing factor for barbers not to use detachable plastic combs or clippers during barbering sessions which poses increased risk of incident cuts and abrasion (Australian Public Health (Hairdressing) Code of Practice 2000 and John 2011). Therefore, the Fijian authorities need to derive the best practices to maintain barbershops standards within the ambit of the current laws. The 1935 Public Health Act and Regulations relating to hair dressers need to be reviewed to address practices based on scientific data and research. 


\subsection{Limitations}

As this study is a cross sectional study, the results of this study can't be generalized to all of Fiji. This study was conducted during the COVID19 pandemic; therefore, the sample size was small due to closer of few barbershops. Furthermore, more recent studies on the topic were not available on the several data base.

\section{Conclusions}

The finding from this study reveal that majority of barbershops did not practice decontamination and sterilization of barbering equipment's. Those that had some form of decontamination such as home bleach and spirits were inappropriate and questionable. Majority barbers did not practice GHP neither cleaned the barbering equipment's with appropriate decontamination solutions nor with hot and sterile cloth. Majority of them did not have proper PPEs and the conditions of many barbershops needed to comply with the requirements of the PH Act. This tends to suggest that authorities need to strengthen enforcement, train and create awareness on all barbershops to standardize the barbering practice. It also suggests that the training contents should place more emphasis on, and employ more appropriate techniques such as demonstration while teaching technical and practical subjects like decontamination. Laxity in monitoring and enforcement of Public Health Act is another contributing factor for noncompliance despite having a stringent Public health laws in place which needs to be reviewed to suite the current and future needs of the country.

\section{Acknowledgements}

We would like to thank all the barbershops for their participation in this study including all those who provided their valuable support in this study such as SCC, FNU CHREC and MOHMS. The authors remain grateful to the barbershop owners who voluntarily allowed to participate in this study.

\section{Competing Interests Statement}

The authors declare that there are no competing or potential conflicts of interest.

\section{References}

Almasi, A., Dargahi, A., Mohammadi, M., Amirian, F., Shokri, A., \& Tabandeh, L. (2016). Comparative study of awareness, attitude, and performance of hairdressers in west regions of Iran in terms of personal hygiene, decontamination of tools and devices, and general status of building. Journal of Chemical and Pharmaceutical Sciences, 9(4), 3056-3062.

Abia, W. A., Fomboh, R., Ntungwe, E., Abia, E. A., Serika, W. A., \& Ageh, M. T. (2016). Assessment of occupational health hazards awareness and common practices amongst barbers and hairdressers in Cameroon. Journal of Public Health in Developing Countries, 2(1), 94-101.

Amodio, E., Di Benedetto, M. A., Gennaro, L., Maida, C. M., \& Romano, N. (2010). Knowledge, attitudes and risk of HIV, HBV and HCV infections in hairdressers of Palermo city (South Italy). European journal of public health, 20(4), 433-437. https://doi.org/10.1093/eurpub/ckp178

Khaliq, A. A., \& Smego, R. A. J. (2005). Barber shaving and blood-borne disease transmission in developing countries: issues in medicine: SAMJ forum. South African Medical Journal, 95(2), 94-96.

Ann, 2006 sterilization. Retrieved March 3, 2007 from http://www: licenses state, US barbers .org

Beyen, T. K., Tulu, K. T., Abdo, A. A., \& Tulu, A. S. (2012). Barbers' knowledge and practice about occupational biological hazards was low in Gondar town, North West Ethiopia. BMC Public Health, 12(1), 1-7. https://doi.org/10.1186/1471-2458-12-942

Catalogue.nla.gov.au. 2021. Public Health (Hairdressing) Code of Practice 2000 | National Library of Australia. Retrieved 15 January, 2021, from https://catalogue.nla.gov.au/Record/1919163

Chanda, S. K., \& Khan, K. H. (2004). Sharing of razor-blade in salons and risks of spreading HIV in Bangladesh. In The 3rd IAS Conference on HIV pathogenesis and Treatment.

Chaudhry, M. A., Rizvi, F., Ashraf, M. Z., Afzal, M., \& Niazi, S. (2010). Knowledge and practices of barbers regarding hepatitis B and hepatitis C in Bahra Kahu, Islamabad-Pakistan. Rawal Med J, 35(1), 37-40. Retrieved May 5, 2015, from http://www.wikipedia.org.com Barber

Correa, M., \& Gisselquist, D. (2006). Reconnaissance assessment of risks for HIV transmission through health care and cosmetic services in India. International journal of STD \& AIDS, 17(11), 743-748. https://doi.org/10.1258/095646206778691068

Downey, C. (2005). Can Saloons spread infections? Third Age Health Encyclopedia. Retrieved July 5, 2007 from 
htt://www.gettingon.org/isi news.htm.

Ibrahim, M. T., Opara, W. E., \& Tanimomo, T. (2007). Knowledge of HIV/AIDS, infection prevention practices and accidental skin cuts in barbing saloons in Sokoto, Nigeria. Nigerian Medical Practitioner, 51(6), 123-127. https://doi.org/10.4314/nmp.v51i6.28857

Muleme, J., Kankya, C., Ssempebwa, J. C., Mazeri, S., \& Muwonge, A. (2017). A Framework for integrating Qualitative and Quantitative Data in Knowledge, attitude, and Practice studies: a case study of Pesticide Usage in eastern Uganda. Frontiers in public health, 5, 318. https://doi.org/10.3389/fpubh.2017.00318

Janjua, N. Z., \& Nizamy, M. A. M. (2004). Knowledge and practices of barbers about hepatitis B and C transmission in Rawalpindi and Islamabad. Journal of Pakistan medical association, 54(3), 116.

Jokhio, A. H., Bhatti, T. A., \& Memon, M. S. (2010). Knowledge, attitudes and practices of barbers about hepatitis $\mathrm{B}$ and $\mathrm{C}$ transmission in Hyderabad, Pakistan. EMHJ-Eastern Mediterranean Health Journal, 16(10), 1079-1084. https://doi.org/10.26719/2010.16.10.1079

John, J. (2011). The knowledge, attitude, practice and perceived barriers towards screening for premalignant cervical lesions among women aged 18 years and above in Songea urban (Ruvuma. Muhimbili University of Health and Allied Sciences).

Kana, F., Ndongmo, C., Kembou, E., \& Kaptue, L. N. (1998). Sensitization of barbers on SIT/AIDS in Bafousson, Cameron International Conference on AIDS.

Khandait, D. W., Ambadekar, N. N., \& Vasudeo, N. D. (1999). Knowledge and practices about HIV transmission among barbers of Nagpur City. Indian journal of medical sciences, 53(4), 167-171.

Kruk, M. E., Gage, A. D., Arsenault, C., Jordan, K., Leslie, H. H., Roder-DeWan, S., ... \& Pate, M. (2018). High-quality health systems in the Sustainable Development Goals era: time for a revolution. The Lancet global health, 6(11), e1196-e1252. https://doi.org/10.1016/S2214-109X(18)30386-3

Laws of Fiji; Public Health Act 1935.

Lopez, A. D., Mathers, C. D., Ezzati, M. D., Jamison, T., \& Murray, C. J. (2006). Changes in individual behavior could limit the spread of infectious diseases. London: Oxford University Press; 2006.

Lyons, G., Roberts, H., Palmer, A., Matheson, M., \& Nixon, R. (2013). Hairdressers presenting to an occupational dermatology clinic in Melbourne, Australia. Contact Dermatitis, 68(5), 300-306. https://doi.org/10.1111/cod.12016

MOHMS, Fiji. Health Information Unit Annual report, 2017, CD section, page 16.

Moda, H. M., \& King, D. (2019). Assessment of occupational safety and hygiene perception among afro-caribbean hair salon operators in Manchester, United Kingdom. International Journal of Environmental Research and Public Health, 16(18), 3284. https://doi.org/10.3390/ijerph16183284

Mutocheluh, M., \& Kwarteng, K. (2015). Knowledge and occupational hazards of barbers in the transmission of hepatitis B and C was low in Kumasi, Ghana. The Pan African Medical Journal, 20. https://doi.org/10.11604/pamj.2015.20.260.4138

Ottawa Charter for Health promotion. (1986). Health Promotion International, 1(4), 405-405. https://doi.org/10.1093/heapro/1.4.405

Salami, K. K., Titiloye, M. A., Brieger, W. R., \& Otusanya, S. A. (2005). Observations of barbers' activities in Oyo State Nigeria: implications for HIV/AIDS transmission. International quarterly of community health education, 24(4), 319-330.

Shahid, A., Nasim, S., \& Memon, A. A. (2013). Insight and educational intervention concerning hepatitis among roadside barbers and their clients in Karachi, Pakistan. The Journal of Infection in Developing Countries, 7(02), 125-129. https://doi.org/10.3855/jidc.2290

The World Bank. Tracking Progress Towards Universal Health Coverage. 2015. Retrieved form https://www.worldbank.org/en/events/2015/06/12/trackinguhc

TAOD \&HPU, 2002, Hairdressing policy, The Department of Alcohol and other drugs and HIV Health Promotion. Retrieved June 2007 from http://www.nsweel.on/docs/des HAIRDRESSING.doc

World Health Organization [WHO]. (2006). The global epidemiology of infectious diseases. Retrieved from http//www.whqlibdoc.who.int/publications /2004/9241592303.pdf 
Wazir, M. S., Mehmood, S., Ahmed, A., \& Jadoon, H. R. (2008). Awareness among barbers about health hazards associated with their profession. J Ayub Med Coll Abbottabad, 20(2), 35-8.

Zewudie, T., Legesse, W., \& Kurkura, G. (2002). Knowledge, attitudes and Practices among barbers in South-western Ethiopia. Afr Newslett on Occup Health and Safety, 12(3), 69-71.

\section{Copyrights}

Copyright for this article is retained by the author(s), with first publication rights granted to the journal.

This is an open-access article distributed under the terms and conditions of the Creative Commons Attribution license (http://creativecommons.org/licenses/by/4.0/). 